\title{
A Study on Improvements of Children's Denim Pants Construction Method Based on Physical Characteristics and Body Areas Worn - Focusing on 4-year-old Boys -
}

\author{
Hye Suk Kim ${ }^{1)}$ and Yun-Ja $\mathrm{Nam}^{2) \dagger}$ \\ ${ }^{1)}$ Dept. of Textiles, Merchandising and Fashion Design, Seoul National University; Seoul, Korea \\ ${ }^{2)}$ Dept. of Textiles, Merchandising and Fashion Design/Research Institute of Human Ecology, Seoul National University; Seoul, Korea
}

\begin{abstract}
The goal of this study is to support the children's pants construction methods that secure clothing size and fit appropriateness through proposed improvements of denim pants construction method focusing on 4-year-old boys. Depths interview on the actual condition, measurements and calculations for positions and ease of the clothing points corresponding to the body points actually worn were conducted for 47 denim pants of nine boys. "Characteristics of the areas worn" and "physical characteristics of lower body" were analyzed, and improvements of 4-year-old children's denim pants construction method were proposed. As the results, the different figures in "characteristics of the areas worn" between the existing children's pants construction methods and children's actual wearing habits were found, and identification of distinct children's lower body from adults' supports that we should avoid tracing adults' methods without reasons. Children's pants construction method on basis of actual wearing should be devised to solve fit problems. Improvements of children's method were proposed such as ease of girth by different area worn, ease of "elastic waist girth", the difference between "elastic waist girth" and "pattern waist girth", and the difference between "pattern waist girth" and "pattern hip girth" as considerations of pants girth items, and appropriate position "clothing waist girth" "pants hip length" level, "pants crotch length" level, "clothing knee length" level, and "pants outside length" level for pattern making as considerations of clothing length items.
\end{abstract}

Key words : children, denim pants, physical characteristics, body areas worn, clothing construction

\section{Introduction}

In regard to clothing habits, children are so active and rough that they fall over frequently, and lack the ability to control rest and other activities(Lee, 1995), and they prefer comfortable clothes and textiles(Lee \& Park, 2008). Therefore, care is required when designing children's clothes. Children gain the ability to do something by themselves and start to express their preference and opinion at the age of 4 or 5(Birren, 1978/1996). They learn to wear clothes on their own and clothes play an important role when used as a tool when children want to draw people's attention(Lee \& Park, 2008).

Children have unique physical characteristics which are different from adults and have growth variables. Therefore, separate studies on children's body characteristics and clothing sizes are necessary. Nevertheless, there aren't many studies subspecialized on children subjects while most studies have focused on adult subjects(Kim \& Nam, 2007). Anthropometric studies on pre-school children are

†Corresponding author; Yun-Ja Nam

Tel. +82-2-880-6844, Fax. +82-2-875-8359

E-mail: yunja@snu.ac.kr limited in comparison with school children, the twenties and the middle-aged(Kim \& Hong, 2001). In addition, children's clothing construction methods have borrowed adults' methods in numerous cases. Therefore, it is required to analyze pre-school children's physical characteristics compared to other ages, and to understand significant points when pre-school children wear their clothes.

In this study, 4-year-old boys were selected as subjects of this study. This is why the age group of 4 has been dealt with negligently in manufacture industry(Lee \& Chun, 2001) and clothing design considering physical conditions except diapers is feasible from the age group of 4 . Lower body shape of the age of 4 is distinctive from the age group of 6(Park, 1998). And the frequency of children's wearing denim pants is increased from the age of 3 or 4 due to the fact that children at this age group begin to go out frequently for social life such as attending kindergarten or nursery schools(Lee \& Park, 2009). Therefore, their denim pants were selected as daily wear to identify their unique characteristics of the areas worn.

Through in depth interviews on the actual condition, the measurements of body and pants, "the characteristics of areas worn" were identified. And then, "the physical characteristics of lower body" were analyzed compared to other age groups, and improve- 
ments of 4-year-old children's denim pants construction method were proposed.

The goal of this study is to support children's pants construction methods that secure clothing size and fit appropriateness through proposed improvements of denim pants construction method based on the physical characteristics of lower body and the characteristics of areas worn focusing on 4-year-old boys.

\section{Review of Literature}

\subsection{Children's physical characteristics}

According to the preceding studies, children's physical characteristics are: first, children grow faster vertically more than horizontally; second, their upper bodies are more developed than their lower bodies due to insufficient lower growth; third, they have round body shapes due to developed subcutaneous fat as well as slim body shapes, and fourth, they have small chest and hip girths, but comparatively thick waist girths, and no curves. Their body depths are thicker than those of adults from the side, their abdomens are protruded and their backs are bent backwards(Kim et al., 2002). As they grow up, their body shapes change into body shapes similar to adults'(Park, 1993), which is also applied to children under the age group of 6 . While upper body shapes generally are curveless between the ages of 3-6, upper body shapes that have been slim and with protruded abdomen at the age of 3 or 4 become larger vertically and horizontally and get flatter from the side at the age of 5 or 6(Kim \& Hong, 2001). Upper body shapes between the ages of 4-6 are classified into 4-year-old type and 6 year-old type and physique elements such as height, length and girth items have the difference between the age groups(Park \& Suh, 1998). Lower body shapes between the ages of 4-6 are classified into 4-year-old type and 6 year-old type on the basis of horizontal sizes and vertical proportions of different areas of the body. With reaching the age of 6 , lower body proportion is increased according to vertical growth, and horizontal growth focusing on width and girth rather than depth results in a flat shape from the side(Park, 1998). Therefore, it is judged that 4-year-old children are more appropriate subjects to devise a clothing construction method than 5-year-old children and a separate study for them is necessary due to the distinctive body characteristics from 6-year-old children.

\subsection{Children's clothing sizes and fit satisfaction}

The Korean standards KS K 9402(2009) and KS K 9403(2009) concerning children clothing sizes for the 7-12 year-old children mark body height and body chest girth items for upper clothes and body height and body waist girth items for lower clothes divided by sex. However, the KS K 0052(2009) for pre-school children only marks height item at the interval of $5 \mathrm{~cm}$ to $125 \mathrm{~cm}$ regardless of sex, and 4-year-old children select size 100 or 105 .

As a study on sizing system for children's clothes, Kim and Sohn(1999) found that sizes of underwear for 0-4-year-old children tend to have $10 \mathrm{~cm}$ intervals, wider than the notation of $\mathrm{KS} \mathrm{K}$ 0052(2009). Kim(2004) suggested a new sizing system for 2-4year-old children finding that heights of 3-year-old children are within 100-105 cm and those of 4-year-old children are within 105$110 \mathrm{~cm}$ and their heights, chest girths and waist girths in 2004 larger than clothing size markings of Korean standard in 1999. According to Lee and Chun(2001), infants' clothes were usually produced for the age below 3 , concentrated on producing for 12, 18 and 24 months by apparel companies. In case of children's clothes, the lowest limits of target age are 3,5 or 7 and most supplies are assigned to the ages between 5 and 11 . They pointed out that the age of 4 lies on the border between infants' and children's clothes and has been dealt with most negligently in apparel industry. A study to develop clothes that fit 4-year-old children well is required due to the fact that clothing design considering only physical elements except diapers is feasible from the age of 4 because diapers are taken off within a 26-30 months period after birth on average(Kim, 2011) and 4-year-old children have distinctive physical characteristics(Park, 1998; Park \& Suh, 1998).

In regard to the study that investigated clothing size awareness or fit satisfaction, it was found that mothers of 3-7-year-old children are dissatisfied with price, change of color or shape, size, textiles, and sewing in order, in other words, they attach more importance to practical use more than to conspicuous consumption(Sin \& Chun, 2010). $\mathrm{Ha}(1987)$ pointed out that multi-purpose and multi-function of detail are preferred for 1-6-year-old children clothes. Oh and No(2012) investigated clothing size awareness of mothers of children who go to kindergarten or nursery school and found that many apparel companies don't follow clothing size markings of the standard so that mothers are in trouble in selecting clothing sizes suitable for children's ages. Most mothers check clothing size markings on labels carefully when purchasing clothes. To be worthy of a notice, the inappropriateness of clothing sizes is of great importance as a reason to exchange children's clothes. Chang and Nam(2006) who searched internet shopping attitude, behavior and satisfaction according to clothing purchasing frequency of internet shoppers for kindergarten children's clothes support this finding. Chang and Nam(2006) found out that clothing quality and inappropriateness of clothing sizes are main reasons of consumers' dissatisfaction. On this wise, It was apparent that checking clothing size markings on labels is an important way for consumers to identify clothing sizes and sizes of children's clothes play an important role as a purchasing factor comparing to those of adults' clothes. 
For the study that studied fit dissatisfaction of different areas of the clothes, $\mathrm{Ha}(1987)$ pointed out the problems to make children's clothes without considering their growth, finding that 1-6-year-old children's clothes are smaller than body measurements in arm scye girth, neck girth, interscye length and crotch length. To see dissatisfying areas related to clothing sizes between the ages of 0-4, children's clothes are smaller than body measurements in order of neck-base girth, abdominal girth, total length · back length, and bigger than body measurements in the order of sleeve length, pants outside length and shoulder width(Kim \& Sohn, 2000).

On this wise, many preceding studies found out general problems and the importance of children's clothing sizes, however, indepth studies revealing clothing size such as adequate ease for children are insufficient. To resolve the current problems of children's clothes, positions and ease corresponding to actual areas worn in consumer's perspective should be revealed practically and concretely because growth factor should be considered as well as current clothing fit.

\subsection{Children's pants construction method}

The reason for fit dissatisfaction children's clothes is that children's clothing construction method to consider children's particularities hasn't been built well, since clothing sizes are closely associated with clothing construction method.

There were some studies that performed on preschool children's anthropometric measurements or somatotypes, however, it is judged that the studies on pants construction method that dealt with preschool children were insufficient, seeing that the cases were mainly focused on elementary school girls(Lee \& Cho, 2008; Seok \& Kim, 1999; Suh, 2003) and a case on preschool children was just Park's study(1992) that developed a shorts construction method. In addition, a case on children's denim pants was only Suh's study(2003) that dealt with school girls although denim pants are daily wear.

As the study that dealt with pants construction method, Lee and Cho(2008) developed a pants block pattern on 9-year-old girls through size analysis and fitting evaluation test of 3 manufacture patterns. $6 \mathrm{~cm}$ as ease of waist girth(pattern waist girth difference), $4 \mathrm{~cm}$ as ease of hip girth(pattern hip girth difference) and fixed values of pattern sizes for other items were suggested, after pointing out that manufacture patterns have excessive ease of waist girth(pattern waist girth difference 7.2-12.2 cm) and ease of hip girth(pattern hip girth difference 7.4-13 cm). Seok and Kim(1999) deducted Rohrer's index, height, lateral malleolus height, ililcrestale girth, thigh girth and weight as variables discriminating 1011-year-old girls' lower body type, and then set ease and dart amount and total crotch length from regression equation consid- ering the difference between girths of convex hull and hip girth and variation of body surface length according to movement. Though a pants block pattern was finally developed, it was the result that gained the minimum ease from body shape without considering consumers' needs. Suh(2003) surveyed on the actual condition of 11-year-old girls' denim products and found that fit satisfaction in terms of shapes was the middle range but inconvenience in terms of shapes was serious though existing denim pants were worn frequently. Inconvenient areas were mainly knee and thigh. They suggested a pants design combining ease addition by cutting lines, use of stretch textile and grain arrangement on the bias to improve the problems. However, it was far from development of a general clothing construction method due to the scope of study for design ideas. Han(2005) developed formal pants construction method of 9-year-old boys through fit evaluation test in terms of shape and daily movements of waist, abdomen, crotch, thigh and knee collecting 6 existing patterns. In consumer survey, pants outside lengths were larger than the body measurements and the satisfaction of abdominal girths was the lowest. $5 \mathrm{~cm}$ as ease of waist girth(pattern waist girth difference), $5 \mathrm{~cm}$ as ease of hip girth(pattern hip girth difference) and fixed values of pattern sizes for crotch length and pants outside length were suggested. Park(1992) suggested a shorts construction method through revising a clothing construction method. The area items were limited just using waist girth, hip girth, pants hem girth and position of waist girth line. Recommendations to design children's clothes were the application of sufficient clothing length and girth considering children's activities, convenience to put on and take off clothes and use of waist belt type flexible to the variance of waist girth.

On this wise, the preceding studies that devised children's construction methods mostly suggested that waist girth and hip girth items as calculated values using ease but other items as fixed values of pattern sizes. Fixed values of areas gained through a fitting evaluation test focusing on one subject age didn't give information of positions and ease of the clothing points corresponding to the body points. Thus, it is judged that those studies had limitation to apply to other aged children. And it is judged that area items used when fitting evaluation were insufficient.

Furthermore, the problem is that many children's clothing construction methods have been traced over adults' without reasons in numerous cases when establishing positions of baseline and ease, which are the basics of clothing pattern. An approach distinctive from adults' clothing construction methods is required when establishing children's clothing construction methods because children have a habit to wear larger clothes than present physique considering future growth(Oh \& No, 2012). Pants waistline is generally placed lower than body waistline for adult male(Choi, 2008; Nam 


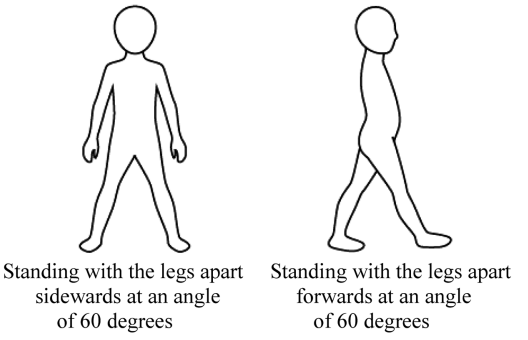

Fig. 1. Postures to estimate fit satisfaction in terms of movement.
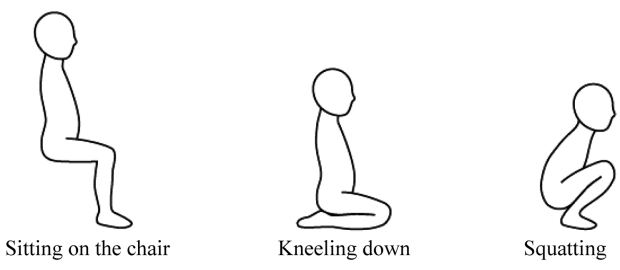

Squatting
\& Lee, 2005), but pants waistline is not lowered for children(Aldrich, 1991; Armstrong, 2010/2011) in construction methods. It is expected that pants have frequently lowered waistline when worn due to children's protruded abdomen, therefore it is necessary to review the location of pants waistline when worn by children.

An additional problem is a large difference in positions of baseline and ease among the existing children's pants construction methods(Aldrich, 1991; Armstrong, 2010/2011; Dressmaker Gakuin, 2002; Heo \& Seo, 2001). Comparing pants block patterns, vertical position of lowered waistline length of pants, clothing hip girth, pants crotch length, clothing knee girth and pants outside length varied according to clothing construction method. And vertical position of pants crotch length and ease of girth of different areas appeared different largely among the sub-divided patterns by fit types. Positions of baseline and ease which are appropriate for children should be proposed through a study.

Therefore, the wearing characteristics would be figured out through investigating positions and ease of different areas of the body based on actual fitting. The limitation of the existing clothing construction methods would be amended through analyzing the wearing characteristics caused by the physical characteristics of children, and the frame of clothing construction method suitable for children would be suggested.

\section{Methods}

\subsection{Survey on the actual condition of denim pants}

As a method of this study, the first step is to research how denim pants are currently worn. Depths interview on the actual condition of 47 denim pants worn by nine 4-year-old boys in the past year who live in Gyeonggi-do in Korea was conducted from March 29th to April 18th in 2012 to know the necessity of the investigation of the characteristics of the areas worn. Actual respondents are nine mothers of $48 \sim 58$-month-old boys who are able to make objective statements. Jersey leggings that have denim appearance were included to investigate denim pants due to the fact that leggings have a small ease and fabric lay close to the areas worn of the body.
In in-depth interviews, the mothers responded to questions such as number of denim pants owned, when, how often and for how long denim pants are worn, fit type and waist belt type, marked size and size awareness, inconvenient items and specific reasons. Fit satisfaction of the areas worn divided into terms of shape and movement was measured using 5-point likert scale. The items of clothing areas used by Wang et al.(2011) and Han(2005) were used for estimated areas of this study, altering for the intent of this study. Fit satisfaction in terms of movement were estimated in five postures which were taken frequently by child subjects in the survey through modifying the postures for estimation of fitness in terms of movement in Kim's study(2009) and in Park's study(1992)(Fig. 1).

\subsection{Investigation of characteristics of the areas worn}

In the second step, anthropometric measurements of the nine 4year-old boys who participated in the survey on the actual condition were taken. The definitions of body dimensions and landmarks were referred to ISO 8559(1989), KS A ISO 8559(2008), the fifth Size Korea(2004) as measurement criteria. All averages of main measurements of this study were within the standard deviation range of average measurements of the fifth Size Korea(2004)(Table 1).

Then, "Lowered waistline length of pants"( $(\mathrm{d} 0)$ were measured from the 47 denim pants used in the survey on the actual condition

Table 1. Anthropometric measurements of 4-year-old boys in this study

(unit : mm)

\begin{tabular}{|c|c|c|c|c|}
\hline \multirow{3}{*}{ Items } & \multicolumn{4}{|c|}{ 5th Size Korea(2004) This study(2012) } \\
\hline & \multicolumn{2}{|c|}{$(\mathrm{N}=208 \sim 210)$} & \multicolumn{2}{|c|}{$(\mathrm{N}=9)$} \\
\hline & Mean & S.D. & Mean & S.D. \\
\hline Body height & 1023.0 & 41.2 & 1043.3 & 27.9 \\
\hline Body crotch height & 423.0 & 27.4 & 424.4 & 21.3 \\
\hline Body chest girth & 548.0 & 29.9 & 562.6 & 24.3 \\
\hline Body waist girth(omphalion) & 509.0 & 38.1 & 507.4 & 25.4 \\
\hline Body hip girth & 555.0 & 39.4 & 555.2 & 35 \\
\hline Weight(kg) & 16.7 & 2.3 & 17.5 & 2.1 \\
\hline $\mathrm{BMI}\left(\mathrm{kg} / \mathrm{m}^{2}\right)$ & $16.0 *$ & - & 16.1 & 1.6 \\
\hline
\end{tabular}


child subjects wearing their own pants. The term "Lowered waistline length of pants" was introduced to find the clothing points corresponding to the body areas actually worn, meaning how low to wear pants from body waist. Omphalion was chosen as body waist level in this study, judged to have little error of measurement. This is why variations of vertical positions of abdominal protrusions occur depending on how bulging children's abdomens are. In additions, it is actually impossible to find the most concave waist level defined in Size Korea(2004; 2011) as 4-year-olds have no curves, and to find the lower ribs used for waist level prescribed in ISO 8559(1989).

In this study, the method of calculations using body and clothing measurements was devised to identify positions and ease of the clothing points corresponding to the body points actually worn(Table 2, Fig. 2). Length or girth items used in analysis of pants products of Yoon's study(2008) were referred and items concerning calf and thigh girth were added for items of this study(Table 2). The first step is to calculate b(anthropometric measurements applied lowered waistline length of pants). Length of $\mathrm{a}$ (anthropometric measurements) minus $\mathrm{d} 0$ (lowered waistline length of pants) is $b$ (anthropometric measurements applied lowered waistline length of pants) that means body length excluding length from omphalion to pants belt. The second step is to search the clothing points corresponding to the body points actually worn considering $\mathrm{d} 0$ (lowered waistline length of pants) and measure clothing lengths or girths at the clothing points, which is c(clothing measurements of the areas worn). The terms "clothing " or "pants $\sim$ " of c(clothing measurements of the areas worn) were measured based on the clothing measurement methods by $\mathrm{Heo}$ and Seo(2001), and Nam and Lee(2005), and girths at the clothing

Table 2. Body and clothing measurement items and calculations

\begin{tabular}{|c|c|c|c|c|}
\hline Classification & $\begin{array}{l}\text { a Anthropometric } \\
\text { measurements }\end{array}$ & $\begin{array}{l}\text { b Anthropometric measurements applied } \\
\text { lowered waistline length of pants }\end{array}$ & $\begin{array}{c}\text { c Clothing measurements of the } \\
\text { areas worn }\end{array}$ & $\begin{array}{l}\text { d Difference between clothing and } \\
\text { body for the areas worn }\end{array}$ \\
\hline \multirow{8}{*}{$\begin{array}{l}\text { Length } \\
\text { items }\end{array}$} & & & & d0 Lowered waistline length of pants \\
\hline & al Body hip length & $\begin{array}{l}\text { b1 Body hip length applied lowered waistline } \\
\text { length of pants }(=\text { a1-d0) }\end{array}$ & c1 Pants hip length & d1 Hip length difference $(=\mathrm{cl}-\mathrm{b} 1)$ \\
\hline & $\begin{array}{l}\text { a2 Body total crotch } \\
\text { length }\end{array}$ & $\begin{array}{l}\text { b2 Body total crotch length applied lowered } \\
\text { waistline length of pants }(=\mathrm{a} 2-2 \times \mathrm{d} 0)\end{array}$ & c2 Pants total crotch length & $\begin{array}{l}\text { d2 Total crotch length difference }= \\
\text { c2-b2) }\end{array}$ \\
\hline & a3 Body crotch length & $\begin{array}{l}\text { b3 Body crotch length applied lowered } \\
\text { waistline length of pants }(=\mathrm{a} 3-\mathrm{d} 0)\end{array}$ & c3 Pants crotch length & $\begin{array}{l}\text { d3 Crotch length difference }(=c 3- \\
\text { b3) }\end{array}$ \\
\hline & $\begin{array}{l}\text { a4 Body mid-thigh } \\
\text { length }\end{array}$ & $\begin{array}{l}\text { b4 Body mid-thigh length applied lowered } \\
\text { waistline length of pants }(=\mathrm{a} 4-\mathrm{d} 0)\end{array}$ & & $\begin{array}{l}\text { d4 Clothing crotch-body mid-thigh } \\
\text { length difference }(=\mathrm{c} 3-\mathrm{b} 4)\end{array}$ \\
\hline & a5 Body knee length & $\begin{array}{l}\text { b5 Body knee length applied lowered } \\
\text { waistline length of pants }(=\text { a5-d0) }\end{array}$ & & \\
\hline & a6 Body calf length & $\begin{array}{l}\text { b6 Body calf length applied lowered waistline } \\
\text { length of pants }(=\mathrm{a} 6-\mathrm{d} 0)\end{array}$ & & \\
\hline & $\begin{array}{l}\text { a7 Body outside leg } \\
\text { length }\end{array}$ & $\begin{array}{l}\text { b7 Body outside leg length applied lowered } \\
\text { waistline length of pants }(=\text { a7-d0) }\end{array}$ & c7 Pants outside length & $\begin{array}{l}\text { d7 Pants outside length difference }= \\
\text { c7-b7) }\end{array}$ \\
\hline \multirow{9}{*}{$\begin{array}{l}\text { Girth } \\
\text { items }\end{array}$} & a8 Body waist girth & & c8 Elastic waist girth & $\begin{array}{l}\text { d8 Elastic waist girth difference }= \\
\mathrm{c} 8-\mathrm{a} 8)\end{array}$ \\
\hline & & & c9 Pattern waist girth & $\begin{array}{l}\text { d9 Pattern waist girth difference }= \\
\text { c9-a8) }\end{array}$ \\
\hline & a10 Body hip girth & & \multicolumn{2}{|c|}{ c10 Pants girth at body hip level d10 Hip girth difference $(=\mathrm{c} 10-\mathrm{a} 10)$} \\
\hline & & & c11 Pattern hip girth & $\begin{array}{l}\text { d11 Pattern hip girth difference }(= \\
\text { c11-a10) }\end{array}$ \\
\hline & a12 Body thigh girth & & c12 Pants thigh girth & $\begin{array}{l}\text { d12 Thigh girth difference }(=\mathrm{c} 12- \\
\text { a12) }\end{array}$ \\
\hline & $\begin{array}{l}\text { a13 Body mid-thigh } \\
\text { girth }\end{array}$ & & $\begin{array}{l}\text { c13 Pants girth at body mid- } \\
\text { thigh level }\end{array}$ & $\begin{array}{l}\text { d13 Mid-thigh girth difference }(= \\
\text { c13-a13) }\end{array}$ \\
\hline & a14 Body knee girth & & $\begin{array}{l}\text { c14 Pants girth at body knee } \\
\text { level }\end{array}$ & $\begin{array}{l}\text { d14 Knee girth difference }=\text { c14- } \\
\text { a14) }\end{array}$ \\
\hline & a15 Body calf girth & & $\begin{array}{l}\text { c15 Pants girth at body calf } \\
\text { level }\end{array}$ & d15 Calf girth difference $(=\mathrm{c} 15-\mathrm{a} 15)$ \\
\hline & a16 Body ankle girth & & c16 Pants hem girth & $\begin{array}{l}\text { d16 Pants hem girth difference }(= \\
\text { c16-a16) }\end{array}$ \\
\hline
\end{tabular}

* Measured for long pants only. 


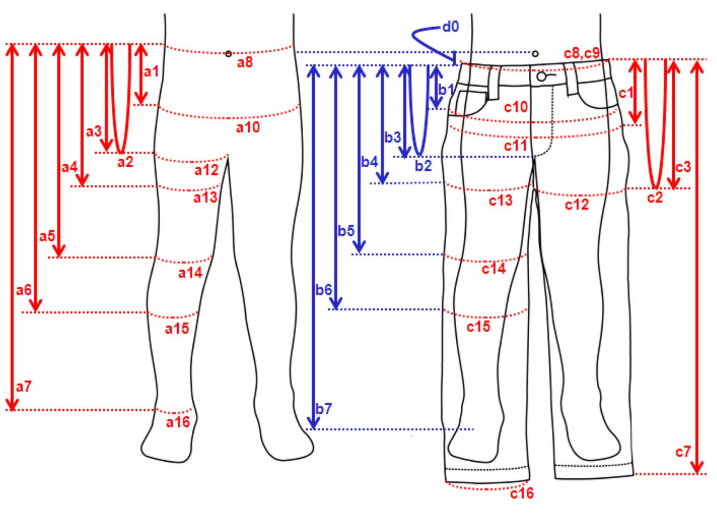

Fig. 2. Measurement items and calculated items.

points corresponding to the body points actually worn were measured for girth items of the terms "pants girth at body level." At last, length of $d$ (difference between clothing and body for the areas worn) equals length of c(clothing measurements of the areas worn) minus b(anthropometric measurements applied lowered waistline length of pants), and girth of d(difference between clothing and body for the areas worn) equals girth of c(clothing measurements of the areas worn) minus girth of a(anthropometric measurements). To avoid confusion whether body items or clothing items, the word "body " or "pants $\sim$ " was added to the beginning of terms.

"Characteristics of the areas worn" were analyzed through technical statistics using the measurements and calculated values from child subjects and their own denim pants.

\subsection{Investigation of physical characteristics of lower body}

As "characteristics of the areas worn" are built from the relationship between clothes and body, we can understand cause of "characteristics of the areas worn", through investigating "physical characteristics of lower body" of 4-year-old boys which are distinctive when compared with other ages.

In the third step, after choosing the body areas representing the characteristics of the areas worn, the average measurements of 4- year-old boys in this study, 10, 15 and 20-24-year-old males in the fifth Size Korea(2004) were collected. In order to account the physical characteristics of lower body of 4-year-old boys, lower body indexes of 4-year-old boys and males at the other ages were comparatively analyzed through technical statistics.

\subsection{Proposition of improvements of denim pants construction method}

Lastly, improvements of 4-year-old children's denim pants construction method were proposed, based on the physical characteristics of lower body, the characteristics of different areas of the body focusing on 4-year-old boys. Specifically, the measurements investigated in wearing aspects in this study were compared with the figures used in the existing children's denim pants construction methods, and then considerations when making pattern were proposed. And the average values applied for improvements of 4-yearold children's denim pants construction method were extracted, through selecting the values of "difference between clothing and body for the areas worn" which were estimated good fit satisfaction of the areas worn over 4 point in both terms of shape and movement.

\section{Results and Discussion}

\subsection{How denim pants are currently worn}

\subsubsection{Number of denim pants in possession}

The range of total pants worn by children in the past year was 9$30 \mathrm{pcs}($ mean $=17.6 \mathrm{pcs}, \mathrm{S} . \mathrm{D}=6.9 \mathrm{pcs})$, the range of denim pants was 3-9 pcs $($ mean $=6.2 \mathrm{pcs}$, S.D $=2.2 \mathrm{pcs})$ from among these. The average number of denim pants worn in the past year was $35.2 \%$ of the average number of total pants.

4.1.2. When, how often and for how long denim pants are worn Children were found to wear denim pants 2 or 3 times a week $($ mean $=8.7$ times $/$ month, S.D. $=2.7$ times $/$ month $)$ and they wore denim pants frequently to go out or for daily activities. The average wearing period after purchase was 1.8 years(S.D. $=0.5$ years).

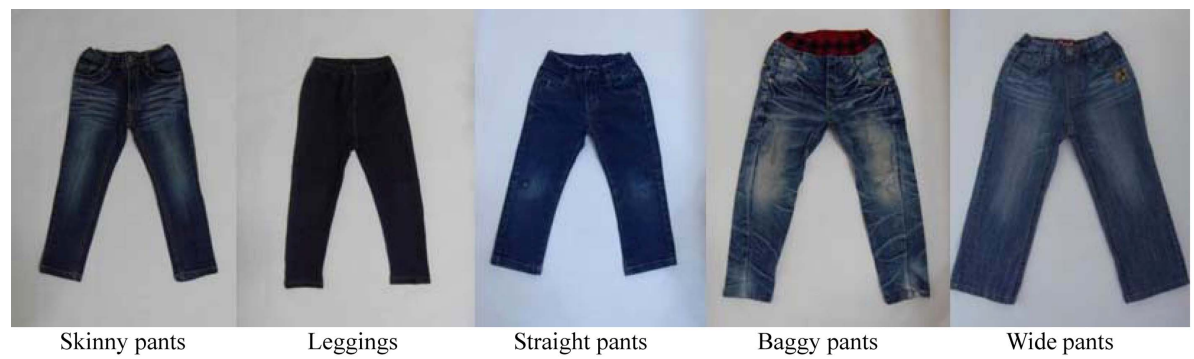

Fig. 3. Fit type of denim pants. 


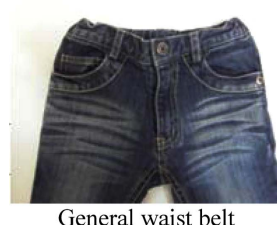

General waist belt

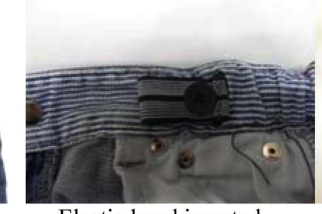

Elastic band inserted inside with adjusting girth

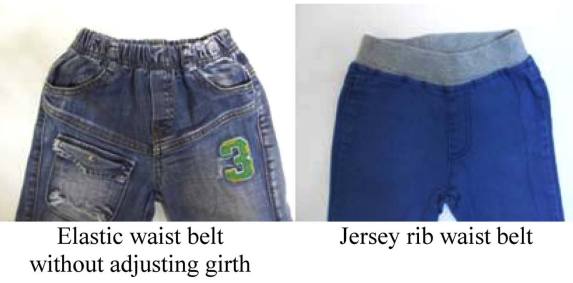

Fig. 4. Waist belt type of denim pants.

\subsubsection{Type of denim pants}

The fit type of denim pants worn were classified into skinny pants, leggings, straight pants, baggy pants and wide pants depending on shape of silhouette after wearing pants(Fig. 3). The denim pants which children possessed the most were wide pants(17 pcs, $36.2 \%$ ), straight pants(15 pcs, $31.9 \%$ ), skinny pants(11 pcs, 23.4 $\%$ ), leggings( 3 pcs, $6.4 \%$ ) and baggy pants( 1 pcs, $2.1 \%$ ) in order.

In addition, the waist belt type of denim pants worn were classified into "general waist belt"(16 pcs, 34.0\%), "elastic waist belt without adjusting girth"(16 pcs, $34.0 \%)$ and "jersey rib waist belt"'(16 pcs, $34.0 \%$ )(Fig. 4). Among these, 1 piece was the combination of front "general waist belt" and back "jersey rib waist belt." And all "general waist belts" were found to have elastic bands inserted inside with adjusting girth. This indicated that each waist belt type was worn similarly frequently and most children's denim pants had elastic elements for waist areas.

\subsubsection{Marked size and size awareness of denim pants}

The marked sizes were not in unison and did not supply information of specific clothing sizes such as the cases of "S", “중 ", "7", "9", "4T" only marked or no marking. There were different markings from the notation of height combined with age in the infants' and children's clothing size standards of Korea(KS K 0052, 2009; KS K 9402, 2009) such as 105(6), 105(7) and 120(11). And there was also a big difference between the marked sizes and the size awareness, and there is a need for denim pants production to be improved to fit the clothing size standards.

Furthermore, the clothing size standard of Korea(KS K 0052, 2009) defines the appropriate size for 4-year-old boys as 100 or 105 , but they were actually found to be wearing sizes 100 to 130 . It was apparent that they wore large pants considering growth rather than good fitness, in that the average of wearing period was 1.81 years.

\subsubsection{Fit satisfaction}

As the result of synthesizing fit satisfaction measured by fit type of denim pants, fit satisfaction in terms of shape the highest are leggings(4.32), baggy pants(4.00), straight pants(3.39), wide pants (3.29) and skinny pants(2.83) in order. The satisfaction of skinny pants was less than middle for all items except "lowered waistline length of pants", showing that skinny pants was the fit type in need to be improved most. Low fit satisfaction of skinny pants was not attributed to slim effect of skinny pants but the problem of clothing appropriateness for different areas worn, in that fit satisfaction was the highest for leggings that has the slimmest effect. In terms of movement, fit satisfaction of skinny pants(3.12) was the lowest compared with the other type of denim pants(wide pants 3.97, leggings 3.93, baggy pants 3.92 and straight pants 3.65)(Table 3). Therefore, it was judged that fit satisfaction might be low if not having fabric elasticity or ease of different areas of pants for movement. The reasons for dissatisfaction of clothing areas were inappropriate "pants outside length", longer or shorter than "body outside leg length", a little ease of "clothing back crotch length", and tight fitting "clothing hip girth" which caused discomfort. And there were a case impossible for a skinny child to wear pants due to too big size only around "body waist girth."

\subsection{Characteristics of the areas worn}

After steps obtaining data of "anthropometric measurements"(a), "anthropometric measurements applied lowered waistline length of

Table 3. Average values of fit satisfaction

\begin{tabular}{|c|c|c|c|c|c|c|c|c|c|c|c|}
\hline \multirow[t]{2}{*}{ Items } & \multicolumn{2}{|c|}{$\begin{array}{l}\text { Skinny pants } \\
\text { (11pcs.) }\end{array}$} & \multicolumn{2}{|c|}{$\begin{array}{l}\text { Leggings } \\
\text { (3pcs.) }\end{array}$} & \multicolumn{2}{|c|}{$\begin{array}{l}\text { Straight pants } \\
\text { (15pcs.) }\end{array}$} & \multirow{2}{*}{$\begin{array}{c}\text { Baggy pants } \\
(1 \mathrm{pcs} .)\end{array}$} & \multicolumn{2}{|c|}{$\begin{array}{l}\text { Wide pants } \\
(17 \text { pcs. })\end{array}$} & \multicolumn{2}{|c|}{$\begin{array}{c}\text { Total } \\
\text { (47pcs.) }\end{array}$} \\
\hline & Mean & S.D. & Mean & S.D. & Mean & S.D. & & Mean & S.D. & Mean & S.D. \\
\hline Fit satisfaction in terms of shape & 2.83 & 0.47 & 4.32 & 1.17 & 3.39 & 0.72 & 4.00 & 3.29 & 0.83 & 3.29 & 0.81 \\
\hline Fit satisfaction in terms of movement & 3.12 & 0.91 & 3.93 & 1.10 & 3.65 & 0.65 & 3.92 & 3.97 & 0.79 & 3.67 & 0.83 \\
\hline
\end{tabular}

Measured with 5-point Likert scale 
Table 4. Average values of "clothing measurements of the areas worn" by fit type of pants

(unit : mm)

\begin{tabular}{|c|c|c|c|c|c|c|c|c|c|c|c|}
\hline \multirow{2}{*}{ Items } & \multicolumn{2}{|c|}{ Skinny pants(11pcs.) } & \multicolumn{2}{|c|}{ Leggings(3pcs.) } & \multicolumn{2}{|c|}{ Straight pants(15pcs.) } & \multirow{2}{*}{$\begin{array}{c}\text { Baggy pants(1pcs.) } \\
\text { Measurement } \\
\end{array}$} & \multicolumn{2}{|c|}{ Wide pants(17pcs.) } & \multicolumn{2}{|c|}{ Total (47pcs.) } \\
\hline & Mean & S.D. & Mean & S.D. & Mean & S.D. & & Mean & S.D. & Mean & S.D. \\
\hline Pants hip length(c1) & 123.5 & 7.4 & 135.3 & 5.5 & 127.1 & 9.4 & 155.0 & 142.0 & 9.1 & 132.9 & 11.9 \\
\hline $\begin{array}{l}\text { Pants total crotch } \\
\text { length(c2) }\end{array}$ & 450.0 & 29.3 & 436.0 & 40.8 & 455.1 & 22.4 & 537.0 & 479.8 & 31.9 & 463.5 & 33.0 \\
\hline Pants crotch length(c3) & 189.3 & 12.0 & 187.3 & 19.4 & 190.2 & 17.5 & 228.0 & 202.5 & 19.5 & 195.1 & 18.4 \\
\hline $\begin{array}{l}\text { Pants outside } \\
\text { length(c7)** }\end{array}$ & 647.1 & 50.6 & 590.0 & 46.4 & 588.5 & 44.7 & 708.0 & 550.3 & 115.2 & 597.7 & 78.8 \\
\hline Elastic waist girth(c8) & 495.8 & 36.3 & 457.3 & 45.4 & 469.4 & 40.6 & 426.0 & 450.0 & 46.7 & 466.3 & 44.4 \\
\hline Pattern waist girth(c9) & 614.4 & 40.6 & 583.3 & 23.9 & 594.5 & 37.3 & 676.0 & 642.0 & 39.3 & 616.9 & 43.6 \\
\hline $\begin{array}{l}\text { Pants girth at body hip } \\
\text { level(c10) }\end{array}$ & 636.4 & 55.1 & 590.0 & 30.3 & 630.0 & 42.4 & 680.0 & 685.4 & 60.6 & 649.9 & 58.3 \\
\hline Pattern hip girth(c11) & 661.0 & 51.8 & 590.0 & 30.3 & 672.9 & 42.3 & 744.0 & 711.9 & 60.2 & 680.7 & 59.2 \\
\hline Pants thigh girth(c12) & 389.6 & 28.9 & 355.3 & 34.4 & 406.5 & 26.8 & 450.0 & 436.0 & 20.8 & 411.2 & 34.2 \\
\hline $\begin{array}{l}\text { Pants girth at body } \\
\text { mid-thigh level(c13)* }\end{array}$ & $\begin{array}{c}372 \\
(1 \mathrm{pcs} .)\end{array}$ & - & $\begin{array}{c}332 \\
(1 \mathrm{pcs} .)\end{array}$ & - & 397.3(3pcs.) & 24.1 & - & 422.7(3pcs.) & 50.8 & 395.5 & 43.3 \\
\hline $\begin{array}{l}\text { Pants girth at body } \\
\text { knee level(c14) }\end{array}$ & 310.0 & 23.9 & 262.0 & 16.4 & 319.3 & 27.9 & 366.0 & 388.6 & 22.7 & 340.5 & 47.6 \\
\hline $\begin{array}{l}\text { Pants girth at body calf } \\
\text { level(c15)** }\end{array}$ & 278.4 & 18.2 & 236.0 & 13.9 & 292.5 & 25.1 & 314.0 & 363.8 & 18.6 & 307.8 & 46.5 \\
\hline Pants hem girth(c16)** & 247.5 & 21.1 & 222.0 & 26.0 & 280.8 & 22.9 & 238.0 & 340.3 & 20.7 & 278.6 & 44.2 \\
\hline
\end{tabular}

* Limited in case that "pants girth at body mid-thigh level" was lower than "pants crotch length" level, meaning it is possible to measure "pants girth at body mid-thigh level."

** The data of "pants girth at body calf level" and "pants hem girth" were limited in case of long pants.

pants"(b) and "clothing measurements of the areas worn"(c, Table 4) on 4-year-old boys and their denim pants, data of "difference between clothing and body for the areas worn"(d) were calculated(Fig. 5, 6, 7). And then, "characteristics of the areas worn" were analyzed with the results of the numerical values on total pants and by fit type of pants, largely divided into "vertical position of the area worn" related to "clothing length items of the area worn", and "ease of girth of the area worn" related to "clothing girth items of the area worn."

As the results, major "characteristics of the areas worn" in terms of "vertical position of the area worn" are first, that "lowered waistline length of pants"(d0) is found for all pants. $\mathrm{d} 0$ (lowered waistline length of pants) is $23.5 \mathrm{~mm}($ S.D. $=14.8 \mathrm{~mm}$ ) on average, and goes up to $64.0 \mathrm{~mm}$. Second, "body hip length"(a1) level is placed higher than expected around clothing hip area. c1(pants hip length) level for pattern making Heo and Seo(2001) is worn $51.9 \mathrm{~mm}$ (S.D. $=16.9 \mathrm{~mm}$ ) lower than al(body hip length) level on average, and a1(body hip length) level is at the 0.42 point of $\mathrm{c} 3$ (pants crotch length). Third, $d 3$ (crotch length difference) is worn longer than expected. d2(Total crotch length difference) is $69.7 \mathrm{~mm}$ (S.D. = 36.1) on average and c3(pants crotch length) level is placed lower $59.4 \mathrm{~mm}($ S.D. $=22.9 \mathrm{~mm}$ ) than a3(body crotch length) level on average. There is a $3.3 \mathrm{~mm}($ S.D. $=21.6 \mathrm{~mm})$ difference between c3(pants crotch length) level and a4(body mid-thigh length) level on average, which means placing at a similar point. The cases that c3(pants crotch length) level is placed lower than a4(body midthigh length) level as well as "body thigh girth" level are 23 pieces of the 47 pieces of pants. In a serious case, c3(pants crotch length) level is located $58.0 \mathrm{~mm}$ lower than a4(body mid-thigh length) level is shown. Fourth, "body knee length"(a5) level is at the $1 / 2$ point of "pants outside length"(c7) on average. Since the average value of $\mathrm{c} 7$ (pants outside length) is $597.7 \mathrm{~mm}($ S.D. $=78.8 \mathrm{~mm}$ ) and the average value of b5(body knee length applied lowered waistline length of pants) is $300.5 \mathrm{~mm}($ S.D. $=20.2 \mathrm{~mm})$, thus a5(body knee length) level is at the 0.50 point of a7(body outside leg length). Fifth, there are some cases that "pants outside length"(c7) is much longer than "body outside leg length"(a7)

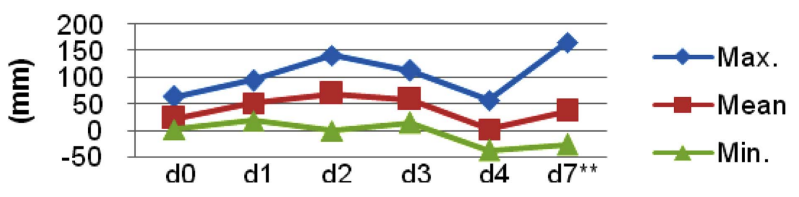

** The data of "pants outside length", were limited in case of long pants.

Fig. 5. Values of the "difference between clothing and body for the areas worn" in terms of "vertical positions of the area worn" of total denim pants. 
level. c7(pants outside length) is $36.8 \mathrm{~mm}$ (S.D. $=49.8 \mathrm{~mm}$ ) longer than a7(body outside leg length) level on average, and the difference goes up to $166.0 \mathrm{~mm}$. Although the average value of $\mathrm{d} 7$ (pants outside length difference) is adequate, fit problems might come up if $\mathrm{c} 7$ (pants outside length) is much longer than a7(body outside leg length) level(Fig. 5).

Major "characteristics of the areas worn" in terms of "ease of girth of the area worn" are first, that pants girth of each area was worn much larger than the body girth of the area at times. Of all pants, the maximum values of ease of girth by the area are $\mathrm{d} 8$ (elastic waist girth difference) $53.0 \mathrm{~mm}$, d9(pattern waist girth difference) $215.0 \mathrm{~mm}$, d10(hip girth difference) $325.0 \mathrm{~mm}$, d11(pattern hip girth difference) $357.0 \mathrm{~mm}$, d13(mid-thigh girth difference) $174.0 \mathrm{~mm}, \mathrm{~d} 14$ (knee girth difference) $212.0 \mathrm{~mm}$, d15(calf girth difference) $184.0 \mathrm{~mm}$ and d16(pants hem girth difference) $182.0 \mathrm{~mm}$. Second, elastic waist girth(c8) and pattern waist girth(c9) are found together because most children's denim pants have elastic elements for waist areas. Through the depths interview, this is why children at this age have difficulty in adjusting openings and zippers by themselves and elastic elements help children put on their pants. The difference between the average value of $\mathrm{c} 8$ (elastic waist girth) $($ mean $=-466.3 \mathrm{~mm}$, S.D. $=44.4 \mathrm{~mm})$ and the average value of $\mathrm{c} 9$ (pattern waist girth) $($ mean $=616.9 \mathrm{~mm}$, S.D. $=43.6 \mathrm{~mm})$ is a great difference of $150.6 \mathrm{~mm}$. Third, there are some cases that "elastic waist girth"(c8) is much smaller than "body waist girth"(a8). The $\mathrm{d} 8$ (elastic waist girth difference) is $-39.6 \mathrm{~mm}($ S.D. $=41.3 \mathrm{~mm}$ ) on average, and the difference goes up to $-113.0 \mathrm{~mm}$. c8(elastic waist girth) is usually smaller than the a8(body waist girth) from the characteristics of elastic elements, but pressure even might be applied to waistline in extreme cases. Fourth, children's denim

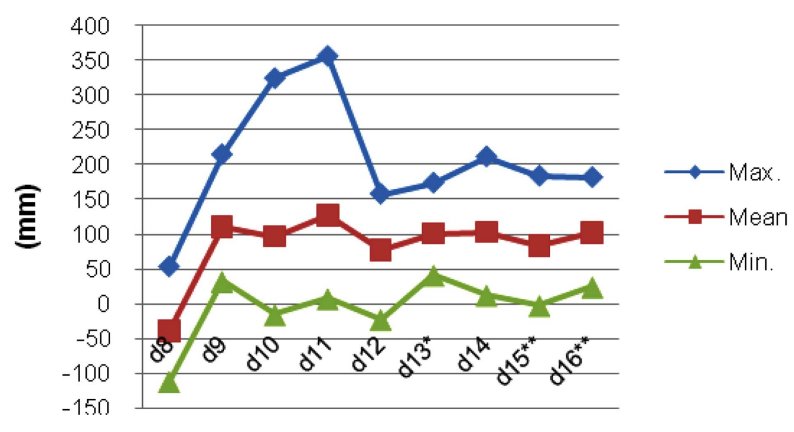

* Limited in case that "pants girth at body mid-thigh level" was lower than "pants crotch length" level, meaning it is possible to measure "pants girth at body mid-thigh level."

** The data of "pants girth at body calf level" and "pants hem girth" were limited in case of long pants.

Fig. 6. Values of the "difference between clothing and body for the areas worn" in terms of "ease of girth of the area worn" of total denim pants. pants have a small difference between "pattern waist girth"(c9) and "pattern hip girth"(c11). There is a small difference of $63.8 \mathrm{~mm}$ between the average value of $\mathrm{c} 9$ (pattern waist girth) $($ mean $=616.9$ $\mathrm{mm}$, S.D. $=43.6 \mathrm{~mm})$ and $\mathrm{c} 11$ (pattern hip girth $)($ mean $=680.7 \mathrm{~mm}$, S.D. $=59.2 \mathrm{~mm}$ ) when making patterns(Fig. 6).

When compared by fit type of pants in relation to the characteristics in terms of "vertical position of the area worn", first, the most average values of $\mathrm{d} 0$ (lowered waistline length of pants) are baggy pants $(28.0 \mathrm{~mm})$, straight pants · skinny pants $(27.1,27.0 \mathrm{~mm})$, wide pants $(19.4 \mathrm{~mm})$ and leggings $(14.7 \mathrm{~mm})$ in that order. Second, the most average values of d1(hip length difference) are baggy pants $(78.0 \mathrm{~mm})$, wide pants $(58.9 \mathrm{~mm})$, straight pants $(47.3 \mathrm{~mm})$, skinny pants $(46.5 \mathrm{~mm})$ and leggings $(45.7 \mathrm{~mm})$ in that order, and the most average proportions of al(body hip length) level to c3(pants crotch length) are leggings(0.48), straight pants(0.42), skinny pants û wide pants(0.41) and baggy pants(0.34). Third, the most average values of $\mathrm{d} 3$ (crotch length difference) are baggy pants $(99.0 \mathrm{~mm})$, wide pants $(63.7 \mathrm{~mm})$, skinny pants $(58.5 \mathrm{~mm})$, straight pants $(56.0 \mathrm{~mm})$ and leggings $(42.3 \mathrm{~mm})$ in that order. Fourth, the most proportions of a5(body knee length) level to c7(pants outside length) are, in that order, wide pants( 0.55$)$, leggings(0.53), straight pants(0.51), skinny pants(0.46) and baggy $\operatorname{pants}(0.43)$ on average. At last, the most proportions of d16(pants hem girth difference) are baggy pants $(116.0 \mathrm{~mm})$, skinny pants $(71.6 \mathrm{~mm})$, straight pants $(23.1 \mathrm{~mm})$ and wide pants $\cdot$ leggings $(11.4,11.3 \mathrm{~mm})$ on average in that order(Fig. 7).

In relation to the characteristics in terms of "ease of girth of the area worn", first, wide pants are estimated to be a fit type of pants extremely larger than body since wide pants have the most average value and maximum value of ease of girth by the area in all items except c8(elastic waist girth). The most average value of ease of leg girths are shown wide pants, baggy pants, skinny pants and leggings in that order. Second, the most difference between the average value of c8(elastic waist girth and) and c9(pattern waist girth) are baggy pants $(250.0 \mathrm{~mm})$, wide pants $(192.0 \mathrm{~mm})$, leggings $(126.0 \mathrm{~mm})$, straight pants $(125.1 \mathrm{~mm})$, skinny pants $(118.6 \mathrm{~mm})$ in that order. Third, the most average value of $\mathrm{d} 8$ (elastic waist girth difference) are skinny pants $(-17.9 \mathrm{~mm})$, straight pants $(-41.6 \mathrm{~mm})$, wide pants

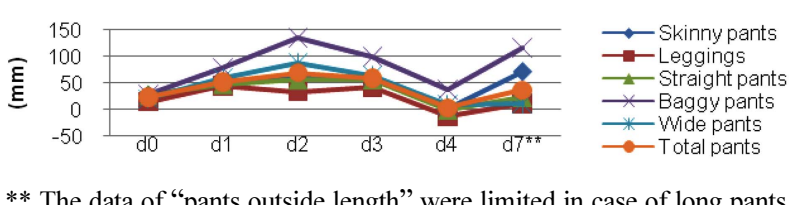

Fig. 7. Average values of the "difference between clothing and body for the areas worn" in terms of "vertical positions of the area worn" by fit type of pants. 


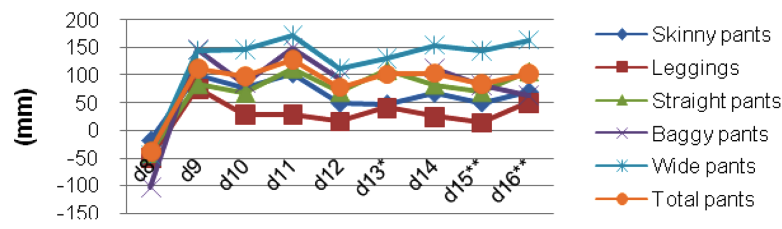

* Limited in case that "pants girth at body mid-thigh level" was lower than "pants crotch length" level, meaning it is possible to measure "pants girth at body mid-thigh level."

** The data of "pants girth at body calf level" and "pants hem girth" were limited in case of long pants.

Fig. 8. Average values of the "difference between clothing and body for the areas worn" in terms of "ease of girth of the area worn" by fit type of pants.

(-46.3 mm), leggings(-49.7 mm), baggy pants(-104.0 mm) in that order. The reason for the lowest pressure of skinny pants is that most skinny pants tend to be "general waist belt" type with low elasticity. Fourth, children's denim pants have a small difference between $\mathrm{c} 9$ (pattern waist girth) and c11(pattern hip girth). The most differences between the average value of $c 9$ (pattern waist girth) and the average value of c11(pattern hip girth) are straight pants $(78.4 \mathrm{~mm})$, wide pants $(69.9 \mathrm{~mm})$, baggy pants $(68.0 \mathrm{~mm})$, skinny pants $(46.6 \mathrm{~mm})$, leggings $(6.7 \mathrm{~mm})$ in that order. The reason for the smallest difference of leggings is the consideration that fabric elasticity can cover lower body curves(Fig. 8).

\subsection{Physical characteristics of lower body}

"Physical characteristics of lower body" of 4-year-old boys distinctive with other ages were analyzed through comparing the average measurements. "Physical characteristics of lower body" can largely be divided into "lower body proportion" and "lower body curves."

"Physical characteristics of lower body" in respect of "lower body proportion" are first, 4-year-old boys have the shortest proportion of lower body length to body height of the compared subjects. The highest "body waist height/height ratio" and "body crotch height/height ratio" are 15-year-olds $(0.60,0.47), 10$-yearolds $\cdot 20 \sim 24$-year-olds $(0.59,0.46)$ and 4 -year-olds $(0.55,0.41)$ in order, showing that 10 -year-old boys have similar proportion to adults(Fig. 9). Thus, making a pattern of 4-year-olds based on a certain higher age might bring about longer c7(pants outside length) than a7(body outside leg length). Extremely longer c7(pants outside length) makes a poor appearance and inconsistency of c7(pants outside length) can cause consumer's dissatisfaction.

Second, 4-year-old boys have the longest proportion of lower leg length to lower body length. "Body knee height/waist height ratio" of 4-year-old boys( $(0.47)$ is the highest ratio of the compared sub-

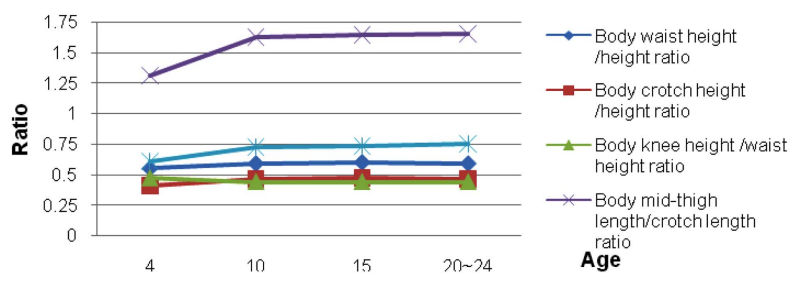

* The ratios calculated as the differences between the associated heights were substituted for "body mid-thigh length", "crotch length" and "body hip length", in that no data of length items are supplied in Size Korea.

Fig. 9. Average "lower body proportion" among males.

jects, and the other ages have the same ratios(0.44)(Fig. 9). This indicates that children around the age of 4 have superior growth of length in lower legs to upper legs because lower body grows in distal area order(Yanagisawa, 1955). The ratio of 4-year-old boys, 0.47 , supports the "characteristic of the areas worn" that a5(body knee length) level is at the $1 / 2$ point of $c 7$ (pants outside length).

Third, 4-year-old boys have the smallest difference between "body crotch height" and "body mid-thigh height", and the smallest proportion of body mid-thigh length to crotch length. The higher the age is, the larger the difference between "body crotch height" and "body mid-thigh height"(4-year-olds $47.0 \mathrm{~mm}, 10$ year-olds $111.0 \mathrm{~mm}$; 15-year-olds $142.0 \mathrm{~mm}$; 20-24-year-olds $148.0 \mathrm{~mm}$ ) and "body mid-thigh length/crotch length ratio"(4-yearolds $1.31,10$-year-olds $1.62 ; 15$-year-olds $1.64 ; 20$-24-year-olds 1.65) are(Fig. 9). The "characteristic of the areas worn" of similar point between $\mathrm{c} 3$ (pants crotch length) level and a4(body mid-thigh length) level(d4 clothing crotch-body mid-thigh length difference mean $=3.3 \mathrm{~mm}, \mathrm{~S} . \mathrm{D} .=21.6 \mathrm{~mm})$ and long ease of crotch length $(\mathrm{d} 3$ crotch length difference) mean $=59.4 \mathrm{~mm}$, S.D. $=22.9 \mathrm{~mm}$ ) is attributed the fact that growth of their upper legs is not enough and their short "body mid-thigh length/crotch length ratio." Thus, a4(body mid-thigh length) level can be placed at or below c3(pants crotch length) level.

Fourth, 4-year-old boys have the shortest proportion of "body hip length"(a1) to "body crotch length"(a3). The highest "body hip length/crotch length ratio" are 20-24-year-olds( 0.75$)$, 15-yearolds(0.73), 10-year-olds(0.72), 4-year-olds(0.61) in order(Fig. 9). In addition, it is judged that c1(pants hip length) level is below a1(body hip length) level when worn because 4-year-old boys have protruded abdomens and tend to wear pants with lowering waistline to prevent pressure by elastic bands.

"Physical characteristics of lower body" in terms of "lower body curves" are found first, 4-year-old boys have few curves, compared to the other ages. The highest "body waist/hip girth ratio", "body waist width/hip width ratio" and "body waist depth/hip depth ratio" are 4-year-olds(0.91, 0.91, 0.95), 10-year-olds(0.88, 0.90, 0.90), 


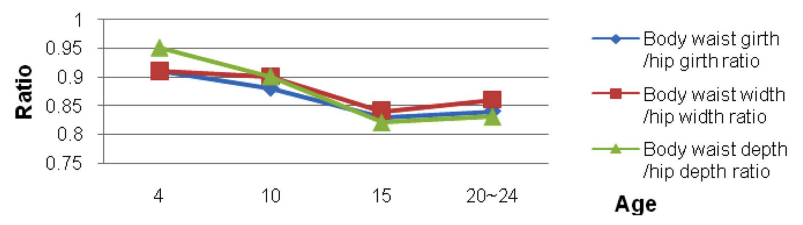

Fig. 10. Average "lower body curves" among males.

20-24-year-olds( $(0.84,0.86,0.83), 15$-year-olds $(0.83,0.84,0.82)$ in order. "Body abdominal girth/hip girth ratio", "body waist width/ hip width ratio" and "body waist depth/hip depth ratio" of 4-yearolds $(0.94,0.95,0.99)$ are higher than those of 20-24-yearolds $(0.87,0.91,0.89)$. Therefore, for 4 -year-olds boys, "physical characteristics of lower body" of few curves and protruded abdomens cause "characteristics of the areas worn" of lowering waistline of pants and a small difference between $c 9$ (pattern waist girth ) and c11(pattern hip girth)(Fig. 10).

\subsection{Improvements of denim pants construction method}

At last, improvements of children' denim pants construction method from "characteristics of the areas worn" and "physical characteristics of lower body" of 4-year-old boys were proposed. Through comparing figures with the existing children's pants construction methods, considerations for denim pants construction method were proposed in terms of clothing length items and pants girth items. In order to be applied for improvements of 4-year-old children's denim pants construction method, the average values of "difference between clothing and body for the areas worn" that have been estimated good fit satisfaction of the areas worn over 4 point were suggested in this step(Table 5).

Considerations of clothing length items when pattern making for 4-year-olds are first, that "lowered waistline length of pants"(d0) should be applied as much as how low they actually wear pants for clothing waist girth line. The existing children's pants construction methods have problems because vertical positions of baseline are inconsistent. Aldrich(1991) stated that there are some children's pants construction methods using low waistlines of pants but body waist girth level is generally used for waistline of pants in case of children's height of 92 122 cm. Armstrong(2010/2011) also use body waist girth level and Heo and Seo(2001) used a higher position as much as waist belt width for clothing waistline. As the results of this study, however, it is judged that children around the age of 4 have the "characteristic of the areas worn" of lowering waistline of pants due to the "physical characteristic of lower body" of fewer curves and more protruded abdomens than other ages of males. The average value that have good fit satisfaction over 4 point, $23.3 \mathrm{~mm}$, can be applied to d0(lowered waistline length of pants) for 4-year-olds.
Second, "pants hip length"(c1) level should be matched to "body hip length"(a1) level that means actual wearing area for clothing hip girth line because a1(body hip length) level of 4-year-olds is at much higher than c1(pants hip length) level and c3(pants crotch length) level in "characteristics of the areas worn". It is important to consider positions of baselines actually worn which are associated with holding ease of girth and can affect fit satisfaction. Heo and Seo(2001) used c3 (pants crotch length) $210.0 \mathrm{~mm}$ and c1(pants hip length) $150.0 \mathrm{~mm}$ for clothing size of 100 and suggested that c1(pants hip length) be measured at 2/3 point of $\mathrm{c} 3$ (pants crotch length) for children's pants, which is the same as position, $2 / 3$ point, in the male adults' pants construction method of Nam and Lee(2005). In this study, however, children's proportion of a1(body hip length) to a3(body crotch length)(body hip length/crotch length ratio) is distinctly smaller than male adults' in "physical characteristics of lower body", and their habit of lowering waistline of pants from protruded abdomen makes $\mathrm{c}$ (pants hip length) level located at higher position. 0.42 point on average can be applied to position of al(body hip length) level to $\mathrm{c} 3$ (pants crotch length). Meanwhile, Armstrong(2010/2011) used 1/2 point as position of c1(pants hip length) to c3(pants crotch length) without applying $\mathrm{d} 0$ (lowered waistline length of pants), which is similar position to this study. When measuring a pants product, it is required to check whether pants have appropriate ease for a10(body hip girth) at the $1 / 2$ point of $\mathrm{c} 3$ (pants crotch length) level without applying $\mathrm{d} 0$ (lowered waistline length of pants).

Third, 4-year-old children's pants should have sufficient "crotch length difference"(d3) matched to "body mid-thigh length"(a4) level for fit satisfaction. c3(pants crotch length) level was determined to be placed $10.0 \mathrm{~mm}$ lower than a3(body crotch length) level for clothing size of 100 by Heo and Seo(2001), and $10.0 \mathrm{~mm}$ lower for general pants, $45.0 \mathrm{~mm}$ lower for baggy pants and 45.0 70.0 mm lower than a3(body crotch length) level, additionally, the same point as a3(body crotch length) level for loose pants and denim pants by Armstrong(2010/2011). Dressmaker Gakuin (2002) determined $160.0 \mathrm{~mm}$ for the value of $\mathrm{c} 3$ (pants crotch length) of clothing size of 100 or 110 . However, $d 3$ (crotch length difference) that have good fit satisfaction is $53.0 \mathrm{~mm}$ on average in this study, different from the existing construction methods in this study. 4-year-olds have a wearing habit with more ease of crotch area than other ages as "characteristics of the areas worn." This is attributed that 4-year-olds have shorter a4(body mid-thigh length) as well as upper legs length as the "physical characteristics of lower body." As the results of depths interview, discomfort caused by long c3(pants crotch length) is not found, thus, the existing construction methods should be modified toward having more d3(crotch length difference). 
Fourth, "clothing knee length" level should be matched to "body knee length"(a5) level because 4-year-olds have higher a5(body knee length) level to a7(body outside leg length), compared with other ages in "characteristics of the areas worn". Though it doesn't matter in case of loose pants, it might be essential in case of fitted pants where "clothing knee length" level is located because fitted pants need delicate wearing shape and ease for wearing sensation than loose pants. "Clothing knee length" level is determined $30.0 \mathrm{~mm}$ higher point by Aldrich(1991) for the children whose height is $920.0 \sim 1220.0 \mathrm{~mm}$. and $25.0 \mathrm{~mm}$ higher point by Armstrong(2011) from the middle of $\mathrm{c} 3$ (pants crotch length) level and c7(pants outside length) level. Gakuin(2002) determined that the difference between "clothing knee length" level and c7(pants outside length) level is $250.0 \mathrm{~mm}$ for clothing size of 100 and $280.0 \mathrm{~mm}$ for 110, and Heo and Seo(2001) determined $235.0 \mathrm{~mm}$ for 100 . As the results of this study, it is apparent that "clothing knee length" level is $74.0 \mathrm{~mm}$ higher point from the middle of c3(pants crotch length) level and c7(pants outside length) level differently from the existing construction methods, because 4-yearolds have longer proportion of lower leg length to lower body length than other ages as the "physical characteristics of lower body." In general of male adults' clothing measurement method, c3(pants crotch length) level is used to measure "clothing knee girth" as the basis(Nam \& Lee, 2005), which is attributed that male adults' pants have small $\mathrm{d} 3$ (crotch length difference) and there are narrow variations of $\mathrm{d} 3$ (crotch length difference). It is proper to measure "clothing knee length" on the basis of pants waistline instead of $\mathrm{c} 3$ (pants crotch length) level because there are wide variations of $\mathrm{d} 3$ (crotch length difference) in case of 4-year-olds. It is reasonable that a5(body knee length) level should be at the $1 / 2$ point of $\mathrm{c} 7$ (pants outside length) level on average in accordance with "characteristics of the areas worn."

Fifth, "pants outside length"(c7) should be tuned to current "body outside leg length"(a7) level, avoiding extremely long "pants outside length"(c7) as mentioned in "characteristics of the areas worn". c7(pants outside length) suggested to be $10.0 \mathrm{~mm}$ longer than a7(body outside leg length) be for clothing size of 100 by Heo and Seo(2001), and the same point for general pants and $25.0 \mathrm{~mm}$ longer by Armstrong(2010/2011). As the results, $27.6 \mathrm{~mm}$ can be applied to $\mathrm{d} 7$ (pants outside length difference) that has good fit satisfaction on average in case of 4-years-olds. Growth factor of children accompanies some $d 7$ (pants outside length difference) for design of pants, we should set $c 7$ (pants outside length) considering children's current a7(body outside leg length) because extremely long $\mathrm{c} 7$ (pants outside length) can make a wearer feel discomfort. Additionally, the average values of ease of girth corresponding to actual wearing area which are suggested in this study till now can be utilized using subdivided ease of girth according to fit type of pants by extension.

Examining the existing children's pants construction methods in relation to pants girth items when making pattern, Armstrong(2010/2011) determined that, in case of pants without elastic band, basic pants need $13.0 \mathrm{~mm}$ d9(pattern waist girth difference), $13.0 \mathrm{~mm}$ d11(pattern hip girth difference) wide pants need 100.0 $150.0 \mathrm{~mm}$ longer than basic pants, and denim pants need $10.0 \mathrm{~mm}$ $\mathrm{d} 9$ (pattern waist girth difference), $6.0 \mathrm{~mm}$ d11(pattern hip girth difference) Heo and Seo(2001), considering ease of girth of pants with elastic band, determined that basic pants for clothing size of 100 need $125.0 \mathrm{~mm}$ d11(pattern hip girth difference) and $36.0 \mathrm{~mm}$ shorter $\mathrm{c} 9$ (pattern waist girth) than $\mathrm{c} 11$ (pattern hip girth) and $280.0 \mathrm{~mm}$ c16(pants hem girth), and basic pants need $145.0 \mathrm{~mm}$ d11(pattern hip girth difference) and $370.0 \mathrm{~mm}$ c16(pants hem girth). Gakuin(2002) suggested $480.0 \mathrm{~mm}$ c9(pattern waist girth), $580.0 \mathrm{~mm}$ c11(pattern hip girth) and $310.0 \mathrm{~mm} \mathrm{c12(pants} \mathrm{thigh}$ girth) for clothing size of 100 in case of pants with partial elastic band backwards.

As considerations of pants girth items, first, 4-year-olds' pants should have sufficient ease of girth by different area worn. We should recognize that children's pants have fundamentally different way to set ease from adults' pants, when considering children's characteristics of ability, behavior and preference in the phrase of development(Lee, 1995; Lee \& Park, 2008) as mentioned previously. In this study, the average values of ease of girth by different area worn that have good fit satisfaction are $108.5 \mathrm{~mm} \mathrm{~d} 9$ (pattern waist girth difference), $111.6 \mathrm{~mm}$ d11(pattern hip girth difference), $82.8 \mathrm{~mm}$ d12(thigh girth difference), $120.5 \mathrm{~mm}$ d13(mid-thigh girth difference), $100.7 \mathrm{~mm}$ d14(knee girth difference), $81.8 \mathrm{~mm}$ d15(calf girth difference) and $100.6 \mathrm{~mm}$ d16(pants hem girth difference), thus, the range of average ease of girth of the areas worn is 77.4 $\sim 127.4 \mathrm{~mm}$. Also notable is the fact that wide pants which don't have elastic fabric but large ease have higher fit satisfaction of girth in terms of movement than leggings. This indicates that only elasticity of fabric is not sufficient and ease should be given together. In addition, specific guidelines about ease of girth of different areas by fit type of pants haven't been suggested in the existing methods. In this study, ease of girth by fit type of pants is suggested, thus, this data can be used to set ease of girth of different areas by pattern designers.

Second, 4-year-olds' pants should be designed considering both "elastic waist girth"(c8) and "pattern waist girth"(c9) separately. The existing methods haven't clearly suggested criteria about gathered ease formed by elastic band such as only suggesting ease for type of pants without elastic band or with elastic band backwards, so there are some difficulties when making patterns. Thus, the 
Table 5. Average values extracted in fit satisfaction evaluation and applied for improvements of 4-year-old boys' denim pants construction method

\begin{tabular}{|c|c|c|c|c|c|c|c|c|}
\hline Classification & Items & Skinny pants & Leggings & Straight pants & Baggy pants & Wide pants & Total & $\mathrm{N}$ \\
\hline \multirow{6}{*}{$\begin{array}{l}\text { Clothing length } \\
\text { items }\end{array}$} & Lowered waistline length of pants(d0) & 26.5 & 14.5 & 24.4 & 28.0 & 21.8 & 23.3 & 19 \\
\hline & Hip length difference(d1) & 37.2 & 36.0 & 42.2 & 78.0 & 54.6 & 46.7 & 26 \\
\hline & Total crotch length difference(d2) & - & 41.0 & 47.2 & 135.0 & 81.2 & 66.5 & 13 \\
\hline & Crotch length difference(d3) & 35.8 & 33.0 & 54.3 & 99.0 & 58.0 & 53.0 & 26 \\
\hline & $\begin{array}{l}\text { Clothing crotch-body mid-thigh length } \\
\text { difference(d4) }\end{array}$ & -18.0 & -21.0 & -1.8 & 38.0 & 2.4 & -2.6 & 26 \\
\hline & Pants outside length difference(d7) & 26.0 & 11.3 & 30.5 & 116.0 & 1.0 & 27.6 & 14 \\
\hline \multirow{9}{*}{$\begin{array}{l}\text { Clothing girth } \\
\text { items }\end{array}$} & Elastic waist girth difference(d8) & -13.5 & -56.0 & -43.0 & -104.0 & -50.5 & -46.8 & 16 \\
\hline & Pattern waist girth difference(d9) & 153.5 & 64.0 & 69.3 & 146.0 & 133.8 & 108.5 & 16 \\
\hline & Hip girth difference(d10) & 105.0 & 19.0 & 83.4 & 85.0 & 124.5 & 96.0 & 18 \\
\hline & Pattern hip girth difference(d11) & 119.0 & 19.0 & 127.2 & - & - & 111.6 & 6 \\
\hline & Thigh girth difference(d12) & 36.5 & 24.0 & 68.8 & 94.0 & 133.2 & 82.8 & 15 \\
\hline & Mid-thigh girth difference(d13) & - & - & 110.0 & - & 131.0 & 120.5 & 5 \\
\hline & Knee girth difference(d14) & 71.0 & 13.0 & 85.1 & - & 168.5 & 100.7 & 16 \\
\hline & Calf girth difference(d15) & 59.0 & 12.0 & 73.1 & 82.0 & 170.0 & 81.8 & 13 \\
\hline & Pants hem girth difference(d16) & 81.0 & 73.0 & 106.9 & 63.0 & 142.0 & 100.6 & 11 \\
\hline
\end{tabular}

Data from the denim pants which were estimated over 4 point in fit satisfaction evaluation.

guideline concerning $\mathrm{d} 8$ (elastic waist girth difference) and $\mathrm{d} 9$ (pattern waist girth difference) separately depending on whether pants have elastic band should be determined. In this study, $-46.8 \mathrm{~mm}$ and $108.5 \mathrm{~mm}$ can be applied to $\mathrm{d} 8$ (elastic waist girth difference) and $d$ 9(pattern waist girth difference) that have good fit satisfaction on average respectively. d8(elastic waist girth difference) has minus figure. This is why waist belt must tighten to hang on body waist area consisting of soft skin.

Third, "elastic waist girth difference"(d8) should be determined at the least pressure to body waist area, and reasonable difference between "elastic waist girth"(c8) and "pattern waist girth"(c9) should be determined to avoid extreme difference. As the results of examination, there are some cases of extremely small c8(elastic waist girth), compared with a8(body waist girth) when actual wearing. Whether pressure is given should be considered by priority. In this study, the difference between c8(elastic waist girth) and c9(pattern waist girth) of 4-year-olds that have good fit satisfaction is found as $155.3 \mathrm{~mm}$.

Fourth, small difference between "pattern waist girth"(c9) and "pattern hip girth"(c11) of 4-year-olds should be determined because they have few curves and protruded abdomens as "physical characteristic of lower body." This is the consideration which is applied well to pants with elastic band in existing methods. In this study, the difference between c9(pattern waist girth) and c11(pattern hip girth) of 4-year-olds that have good fit satisfaction is found as $3.1 \mathrm{~mm}$.

\section{Conclusions}

In this study improvements of children's denim pants construction method which is overlooked in the existing children's pants construction methods were suggested, through analyzing physical characteristics of lower body and characteristics of different areas of the body of 4-year-old boys.

In the survey on the actual condition of denim pants, it was found that children wore denim pants frequently as daily wear and they wore larger pants than their physique considering growth despite defined by clothing size standards. Children's wearing tendency was identified through classifying fit type and waist belt type of denim pants. It was figured out that slim fitting pants were preferred and there are fit problems by different area worn, which can be solved by comfortable fabric or appropriate ease. Thus, we identified the need to propose a clothing construction method dealing with positions and ease of the clothing points corresponding to the body areas actually worn in clothing construction field.

In all "characteristics of the areas worn" except the characteristic concerning the difference between "pattern waist girth"(c9) and "pattern hip girth"(c11), different figures between the existing children's pants construction methods and children's actual wearing habits were found. This is attributed that children's clothing construction methods have been traced over adults' without considering children's particularities. Identification of distinct children's lower body from adults' supports that we should avoid tracing 
adults' methods without reasons, and children's pants construction method on basis of actual wearing should be devised to solve fit problems. In this study, based on analysis of "characteristics of the areas worn" and "physical characteristics of lower body" of 4-yearold boys, improvements of children's denim pants construction method were proposed such as ease of girth by different area worn, d8(elastic waist girth difference), the difference between "elastic waist girth"(c8) and "pattern waist girth"(c9), and the difference between "pattern waist girth"(c9) and "pattern hip girth"(c11) as considerations of pants girth items, and appropriate position "clothing waist girth" "pants hip length"(c1) level, "pants crotch length"(c3) level, "clothing knee length" level, and "pants outside length"(c7) level for pattern making as considerations of clothing length items.

We newly suggested "characteristics of the areas worn" through conceptualizing actual wearing habits to complement preceding studies that only focus on physical characteristics such as body shape. Variables such as "lowered waistline length of pants"(d0), "clothing measurements of the areas worn"(c) and "difference between clothing and body for the areas worn"(d) were introduced in order to account "characteristics of the areas worn", and the method of calculations using body and clothing measurements was newly devised in order to identify positions and ease of the clothing points corresponding to the body areas actually worn. Furthermore, there are problems that the existing children's pants construction methods haven't determined pattern sizes concretely by fit type of pants, thus, range of the average values applied by fit type of pants for improvements of 4-year-old children's denim pants construction method were suggested in this study. We need to subdivide and study children's clothing construction methods by fit type of pants like adults'

"Characteristics of the areas worn" and improvements of children's denim pants construction methods proposed in this study can be applied to clothing pattern design and establishment of clothing measurement methods that can aid applications of clothing product size. The results are also expected to improve predictability of size and fit appropriateness when consumers purchase clothes based on "characteristics of the areas worn" as well as "physical characteristics."

The subjects of this study were limited to 4-year-old boys, but there is a need to expand a study to girls and children of other ages. Additionally, physical characteristics of lower body of 4-year-olds were found different from 10-year-olds, thus, those proposed improvements for 4-year-olds is inappropriate to school-age children. Within childhood, clothing construction method should be established with divided into age groups of distinctive physical characteristics.

However, it is meaningful that this study focused the age group treated carelessly until now. In terms of method, we tried to acquire the accuracy of data, and figure out specific and reliable reasons through depths interview to supplement a small number of questionnaires, 47 pieces. Subjects' physique conditions and fabric characteristics were not controlled due to the method to research the actual condition. Through dealing positions and ease of the areas by degrees with controlled other variables, further studies including laboratory research could lead to clothing construction methods with a higher degree of completion.

\section{Acknowledgments}

This study was supported by the Standardized Technology Development Project 'Establishment of Digital Human and Apparel Product Standards Using IT and Fashion Convergence Technology' (10041517) funded by the Ministry of Trade, Industry and Energy, and the 'BK21 Plus' Project funded by the National Research Foundation of Korea in South Korea.

\section{References}

Aldrich, W. (1991). Metric pattern cutting for children's wear -From 2-14 years (2nd Ed.). BSP Professional Books, 96-103.

Armstrong, H. J. (2011). Patternmaking for fashion design (J. S. Kim, Y. S. Kim, S. H. Ryu, S. a. Gwan, \& Y. J. Nam, Trans.) Seoul: Yehaksa. (Original work published 2010)

Birren, F. (1996). Color and human response (J. H. Kim, Trans.). Seoul: Sigongsa. (Original work published 1978)

Chang, S. K., \& Nam, E. K. (2006). Internet shopping attitude, shopping behavior, and shopping satisfaction according to purchasing frequency of internet shoppers for children's clothing. The Research Journal of the Costume Culture, 14(6), 1027-1041.

Choi, Y. R. (2008). Menswear classic pattern. Seoul: Kyohakyongusa.

Dressmaker Gakuin (2002). Doreme fashion zokekoza 8 BabyKodomofu. Tokyo: JOIE. Inc.

Ha, K. W. (1987). Study of the infant's clothing based on specific characteristics. Unpublished masters dissertation, Ewha Womans University, Seoul.

Han, J. Y. (2005). Patterns of tailored suits and formal jackets for children. Journal of the Korean Home Economics Association, 43(4), 97-110.

Heo, I. A., \& Seo, Y. H. (2001). Toddlers wear. Seoul: Kyohaksa publishing Co.

ISO 8559. (1989). Garnent construction and anthropometrics surveys body dimensions. Reference no. 8559-1989, Geneva: International Organization for Standardization.

Kim, H. J., \& Hong, J. M. (2001). The study of the upper body somatotype for the pre-school children's clothing construction (Part 1) - For the male children from 3 to 6 years old-. Korean Journal of Human Ecology, 10(1), 73-82.

Kim, I. S., Seok, H. J., Bang, E. Y., Kim, Y. M., Sung, E. J., Kim, D. H., \& Lee, E. J. (2002). A study on fitness and awareness of sizing 
system of kids' clothes - Focusing on a first to third year kids in elementary school-. Journal of the Korean Home Economics Association, 40(12), 119-129.

Kim, J. (2004). A study on toddlers' body forms and their apparel sizes -Focused on those toddlers aged 2 - 4. Unpublished doctoral dissertation, Sookmyung Womans University, Seoul.

Kim, J. Y., \& Sohn, H. S. (2000). A study on fitness and awareness of sizing system of infants wear. The Research Journal of the Costume Culture, 8(2), 272-281.

Kim, J., \& Sohn, H. S. (1999). A study on sizes specifications of infants`apparels. The Research Journal of the Costume Culture, 7(6), 1015-1025.

Kim, J., \& Sohn, H. S. (2004). A study on the underwear pattern sizes among toddlers` brands. Journal of fashion business, 8(1), 133140.

Kim, S. Y. (2009). Establishing quantitative evaluation standards for pants fit. Unpublished doctoral dissertation, Seoul National University, Seoul.

Kim, S. Y., \& Nam, Y. J. (2007). Development the optimal size system and application for children`s ready-to-wear -Based on elementary school boys-. Journal of the Korean Society of Clothing and Textiles, 31(3), 364-375.

Kim, Y. J. (2011, February 28). Time when to take off diapers is delayed. Hankyoung.com. Retrieved June 11, 2012, from http://www. hankyung.com/news/app/newsview.php?aid=2011022893857

KS A ISO 8559. (2008). Garment construction and anthropometric survey. Reference no. KS A ISO 8559-2008, Gwacheon: Korean Agency for Technology and Standard.

KS K 0052. (2009). Sizing systems for infant's garments. Reference no. KS K 0052-2009, Gwacheon: Korean Agency for Technology and Standard.

KS K 9402. (2009). Sizing systems for boy's garments. Reference no. KS K 9402-2009, Gwacheon: Korean Agency for Technology and Standard.

KS K 9403. (2009). Sizing systems for girl's garments. Reference no. KS K 9403-2009, Gwacheon: Korean Agency for Technology and Standard.

Lee, H. O., \& Cho, K. S. (2008). A study on the development of pants for daily use appropriate for Korean school girls aged 6 to 11 . Journal of the Korean Society of Costume, 58(8), 47-62.

Lee, J. Y., \& Chun, J. S. (2001). A study on garment sizing systems for infants and children. Journal of the Korean Society of Clothing and Textiles, 25(6), 1046-1056.

Lee, O. S. (1995). A study on the physical activities for infant development. Journal of Jangan University, 15(1), 584-610.

Lee, Y. H., \& Park, H. W. (2008). A study on the design development for toddlers' playwear. Proceedings of the international conference on the Korean Society of Clothing and Textiles, 2008, pp. 207-210.
Lee, Y. H., \& Park, H. W. (2009). Design development for toddler`s playwear. Journal of the Korean Society of Clothing and Textiles, 33(8), 1227-1240.

Nam, Y. J., \& Lee, H. S. (2005). Menswear classic pattern. Seoul: Kyohak Publishing Co.

Oh, S., \& No, E. H. (2012). A research on mothers' size-recognition and their purchase characteristics for the fitness of infant's apparels. Korean Journal of Child Education and Care, 12(4), 209-227.

Park, C. M. (1998). Classification of lower body for pre-school children's apparel design. The Research Journal of the Costume Culture, 6(4), 678-687.

Park, C. M., \& Suh, M. A. (1998). Classification of the somatotype for pre-school children`s clothing construction. The Research Journal of the Costume Culture, 6(3), 201-216.

Park, E. S. (1993). A study on the variations of the body surface on upper arms and pattern construction of school-aged children. Unpublished master's thesis, Yeonsei University, Seoul.

Park, J. S. (1992). A study of the use of the patterns of children's clothes. Journal of the Korean Home Economics Association, 30(1), 67-86.

Seok, E. Y., \& Kim, H. K. (1999). Pants basic pattern design and dress form development through somatotype for elementary school girl's lower body type analysis. Proceedings of the international conference on the Korean Society of Clothing and Textiles. 1999, pp. $53-54$.

Sin, S. M., \& Chun, J. S. (2010). A study on the satisfaction according to purchase characteristics of infants' clothing. Proceedings of the international conference on the Korean Society of Clothing and Textiles, 2010, pp. 227-228.

Size Korea. (2004). 5th Size Korea national sizing survey in South Korea. Retrieved July 11, 2012, from http://sizekorea.kats.go.kr

Size Korea. (2010). 6th Size Korea national sizing survey in South Korea. Retrieved July 11, 2012, from http://sizekorea.kats.go.kr

Suh, S. H. (2003). A development of easy-to-move jean jacket \& pants for school. Unpublished master's thesis, Ewha Womans University, Seoul.

Wang, Y. J., Mok, P. Y., Li, Y., \& Kwok, Y. L. (2011). Body measurements of Chinese males in dynamic postures and application. Applied Ergonomics, 42, 900-912.

Yanagisawa, S. (1955). Clothing somatology. Tokyo: Koseikan.

Yoon, M. K. (2008). Study on the pattern design for mass customization according to the styles of women's pants using $3 D$ body scan data. Unpublished doctoral dissertation, Seoul National University, Seoul.

(Received 16 December 2013; 1st Revised 20 January 2014; 2nd Revised 4 June 2014; Accepted 13 June 2014)

Copyright (C) 2014 (by) the authors. This article is an open access article distributed under the terms and conditions of the Creative Commons Attribution license (http://creativecommons.org/licenses/by/3.0/), which permits unrestricted use, distribution, and reproduction in any medium, provided the original work is properly cited. 